\title{
Zonasi Potensi Airtanah Akuifer Bebas Di Cekungan Airtanah Majenang, Kabupaten Cilacap, Jawa Tengah
}

\section{(Zoning Potential of Groundwater Free Aquifers in Majenang Hyacinth Water, Cilacap District, Central Java)}

\author{
Mahira Anaqah Huwaina ${ }^{1}$, Thomas Triadi putranto ${ }^{1}$, Narulita Santi ${ }^{1}$ \\ ${ }^{1}$ Departemen Teknik Geologi Fakultas Teknik Universitas Diponegoro
}

\begin{abstract}
Majenang Groundwater Basin is located in Cilacap Regency, Central Java. There is an increase of its usage every year. Because of that, it is necessary to make groundwater zonation to get an overview of the potential zonation, specifically in unconfined aquifer. The methods used in this study is measuring water table, sampling 17 samples of groundwater and pumping test to get the quantity of groundwater. Based on the measurement of known water table, it flows from the side of basin to the center of basin. It has a value of water level between 0.1-4.5 mbgl and water table 33.3-119.9 masl. Pumping test data processing generates characteristic data aquifers, with value of transmisivity $(T)$ is $2.9-11.3 \mathrm{~m}^{2} /$ day, hidrolic conductivity $(K)$ is 0.7-4.9 m/day, maximum debit is 2.3-3.6 L/day and optimum debit is 2.0-2.9 $L /$ day. Based on the result of quantity data, it has a medium potential zone for the unconfined aquifer.
\end{abstract}

Keywords: Majenang Groundwater Basin, Unconfined Aquifer, Pumping Test, Quality, Groundwater Potential Zone

\section{Pendahuluan}

Cekungan airtanah adalah suatu wilayah yang dibatasi oleh batas hidrogeologi dan merupakan tempat semua proses pengimbuhan, pengaliran, dan pelepasan airtanah berlangsung (Peraturan Menteri ESDM No. 2 Tahun 2017). Cekungan Airtanah (CAT) Majenang merupakan cekungan airtanah dalam provinsi yang terletak di wilayah administrasi Kabupaten Cilacap, Provinsi Jawa Tengah.Pemanfaatan airtanah di wilayah ini mengalami peningkatan setiap tahunnya, akibat kenaikan jumlah penduduk. Menurut data Badan Pusat Statistik (BPS) Kabupaten Cilacap (2016), jumlah penduduk Kabupaten Cilacap pada akhir tahun 2010 sebesar 1.748.705 jiwa dan pada akhir 2015 sebesar 1.780 .533 jiwa. Berdasarkan data kependudukan tersebut dan asumsi kebutuhan air bersih yang menerapkan standar sesuai Ditjen Cipta Karya PU (1996), kebutuhan air bersih di Kabupaten Cilacap sebesar 80 L/orang/hari dengan peningkatan kebutuhan air sebesar $185.876 \mathrm{~m}^{3} /$ tahun.

\footnotetext{
* Korespodensi Penulis: (Mahira Anaqah Huwaina) Departemen Teknik Geologi Fakultas Teknik Universitas Diponegoro
}

Angka kebutuhan air bersih diperkirakan akan terus meningkat seiring dengan meningkatnya laju pertumbuhan penduduk pada CAT Majenang. Sementara, distribusi airtanah kemungkinan akan terus menurun akibat berkurangnya wilayah pengisian/recharge di CAT Majenang.Oleh karena itu, perlu dilakukannya pembuatan zona potensi airtanah berdasarkan kondisi kualitas dan kuantitas airtanah CAT Majenang.

Tujuan dari dilakukannya penelitian ini adalah untuk mengetahui kondisi muka airtanah bebas daerah penelitian, kualitas airtanah daerah penelitian dan potensi akuifer bebas di CAT Majenang berdasarkan data kuantitas yang didapat dari hasil uji pemompaan/pumping test.

Lokasi penelitian terletak pada Cekungan Airtanah (CAT) Majenang, Kabupaten Cilacap, Jawa Tengah (Gambar. 1). Secara koordinat Universe Transverse Mercator (UTM) Zona 49S, lokasi penelitian terletak diantara garis 245995$263138 \mathrm{mT}$ dan 9193693-9180784 mU, berada dalam wilayah Kabupaten Cilacap, dengan luas cekungan sebesar $108 \mathrm{~km}^{2}$ (Peraturan Menteri ESDM No. 2 Tahun 2017). 


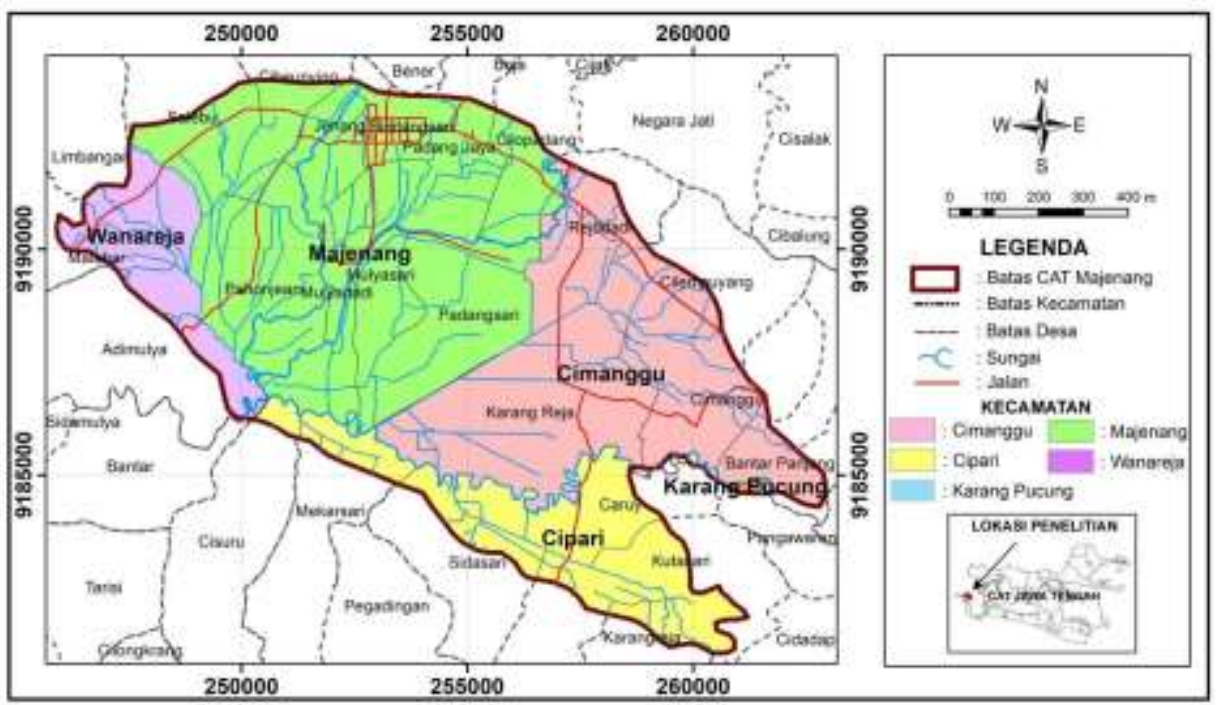

Gambar 1. Peta Administrasi CAT Majenang

\section{Geologi Regional}

Daerah penelitian terdapat pada peta geologi regional lembar Majenang (Kastowo dan Suwarna, 1996). Berdasarkan peta tersebut, dapat diketahui bahwa litologi yang terdapat di CAT Majenang didominasi oleh Endapan Aluvium (Qa), Kipas Aluvium (Qf), Formasi Tapak (Tpt), Formasi Halang (Tmph), dan Formasi Kumbang (Tmpk).

Endapan Aluvium tersusun atas sedimen berukuran kerikil, pasir, dan lempung. Kipas Aluvium tersusun atas sedimen berukuran kerikil dan bongkah, pasir tufa, dan andesit berukuran kerakal dan tanah laterit. Formasi Tapak tersusun atas batupasir, batupasir sisipan napal pasiran dan batugamping.Formasi Halang tersusun atas batupasir tufaan, konglomerat, napal, batulempung, dan breksi andesit.Formasi
Kumbang tersusun atas lava andesit, breksi, tufa, dan napal.

Struktur geologi yang berkembang di daerah penelitian adalah Sesar Naik, Sesar Geser Sinklin dan Antiklin.Struktur tersebut terbentuk akibat adanya kegiatan tektonik yang terjadi selama Pliosen-Pleistosen. Berdasarkan peta geologi regional (Gambar. 2), proses pembentukan CAT Majenang berawal dari terbentuknya sesar naik dan sesar geser. Sesar tersebut menjadikan bagian utara dan selatan cekungan menjadi daerah tinggian. Struktur Sinkin, Antiklin dan Sinklin di daerah penelitian menyebabkan daerah CAT Majenang menjadi sebuah cekungan. Proses selanjutnya adalah terbentuknya Endapan Aluvium akibat adanya proses transportasi batuan yang berada di wilayah tinggian dan terbawa oleh arus sungai, sehingga terendapkan di wilayah rendahan cekungan.

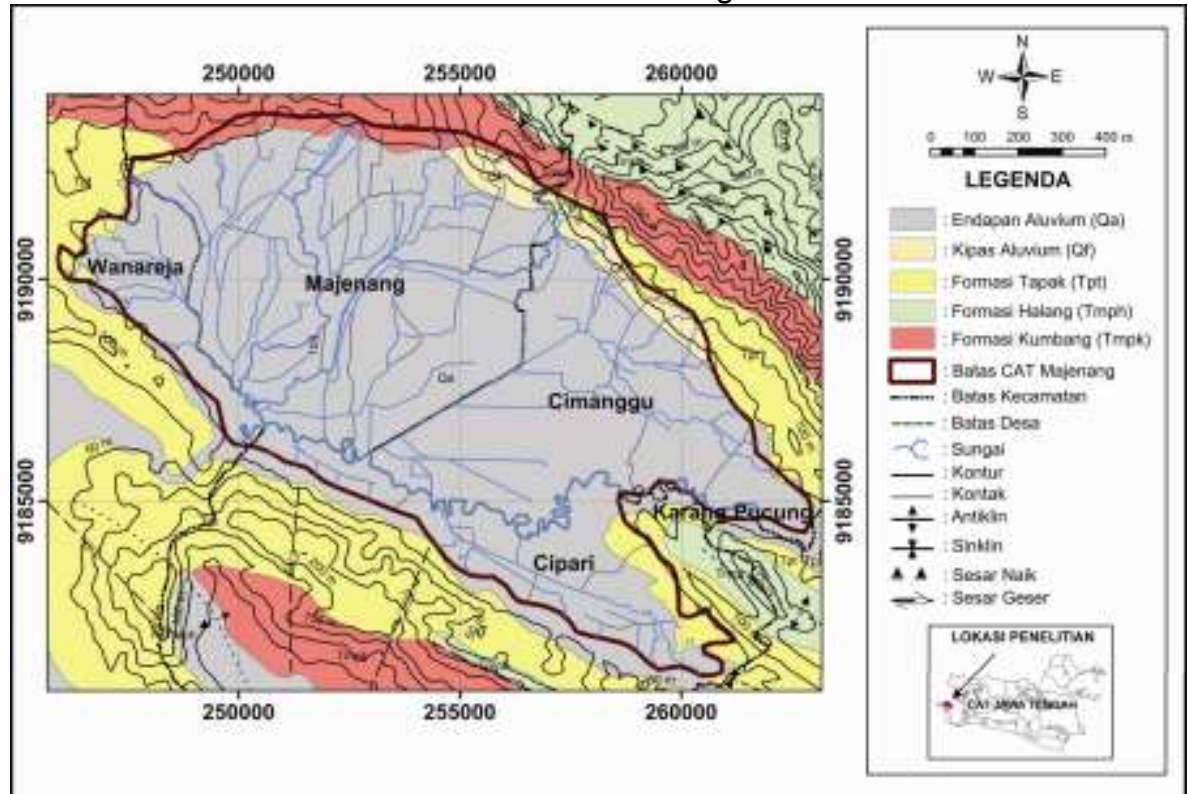

Gambar 2.Peta Geologi Regional CAT Majenang 


\section{Hidrogeologi Regional}

Daerah penelitian termasuk ke dalam Peta Hidrogeologi Regional Lembar Pekalongan (Tabrani, 1984).CAT Majenang memiliki batas cekungan airtanah berupa batas tanpa aliran.Batas tanpa aliran merupakan batas cekungan yang menunjukan tidak terjadinya aliran airtanah di daerah batas cekungan jika dibandingkan dengan aliran pada akuifer
utama.CAT Majenang memiliki tipe batas tanpa aliran eksternal, dimana kontak dari adanya akuifer dan bukan akuifer terjadi pada arah mendatar atau lateral (Bonstra dan de Ridder, 1981 dalam Danaryanto dkk, 2005). Berdasarkan peta hidrogeologi, CAT Majenang memiliki akuifer dengan tipe aliran melalui ruang antar butir, dengan produktivitas tinggi, keterusan sedang-tinggi.

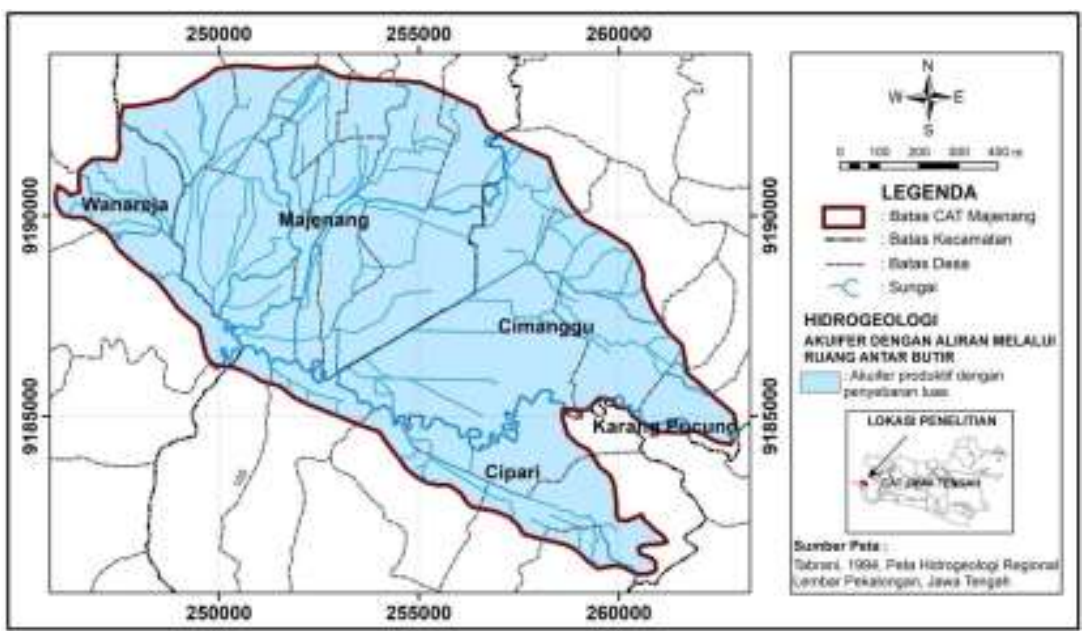

Gambar 3.Peta Hidrogeologi Regional CAT Majenang

\section{Metode Penelitian}

Dalam melakukan metode ini, digunakan data primer dan data sekunder.Data primer yang digunakan berupa data pengukuran muka airtanah CAT Majenang, data kualitas airtanah dan data uji pemompaan/pumping test.Data sekunder yang digunakan adalah Peta Geologi Regional Lembar Majenang dan Peta Hidrogeologi Penelitian Lembar Pekalongan.Dalam pengambilan data primer, selain data utama, dilakukan pengambilan data letak geografis, yaitu data koordinat dan data elevasi.

\section{Kedalaman Muka Airtanah}

Data kedalaman muka airtanah akuifer bebas didapat dengan melakukan pengukuran pada sumur gali dengan menggunakan pita ukur yang diukur dari permukaan tanah hingga permukaan airtanah. Dalam penelitian, terdapat 45 sumur gali yang diukur kedalaman muka airtanahnya.Dari data muka airtanah bebas tersebut, dilakukan interpolasi menggunakan software surfer 11 untuk mengetahui pola arah aliran muka airtanah bebas di CAT Majenang.

\section{Kualitas Airtanah}

Data kualitas airtanah merupakan data yang didapat dari pengambilan sampel air pada sumur gali tempat pengambilan data uji pemompaan/pumping test. Data kualitas airtanah pada penelitian ini mengacu pada Peraturan Menteri Kesehatan No. 492 Tahun 2010 tentang kualitas air minum. Sehingga, hasil akhir dari data kualitas ini digunakan untuk mementukan apakah airtanah di CAT Majenang dapat digunakan sebagai air minum yang baik atau tidak.

\section{Uji Pemompaan/Pumping Test}

Data uji pemompaan digunakan untuk mengetahui debit airtanah, sehingga, diketahui kemampuan sumur dalam memproduksi airtanah dan nilai kelulusan airtanah pada CAT Majenang (Sighal dan Gupta, 1999 dalam Kumar, T. J. R., dkk 2014).Dalam melakukan uji pemompaan, dilakukan uji pemompaan long period test (uji pemompaan menerus). Uji pemompaan dilakukan dengan cara memompa air dari suatu sumur dengan debit tertentu, mengamati penurunan muka air selama pemompaan berlangsung, dan mengamati pemulihan kembali muka air setelah pompa dimatikan sesuai dengan waktu yang sudah ditentukan.

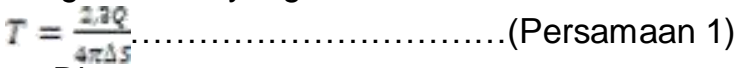

$$
\begin{aligned}
& \text { Dimana: } \\
& \mathrm{T}=\text { Koefisien transmisivitas }\left(\mathrm{m}^{2} /\right. \text { hari) } \\
& \mathrm{Q}=\text { Debit pemompaan ( } \mathrm{m}^{3} / \text { hari) }
\end{aligned}
$$


Promine Journal, June 2017, Vol. 5 (1), page 41 - 50

$\Delta \mathrm{S}=$ Kemiringan pada grafik time-drawdown yang dinyatakan sebagai drawdown antara dua waktu

$K=\frac{F}{D}$. (Persamaan 2)

Dimana:

$\mathrm{K}=$ Koefisien konduktivitas ( $\mathrm{m} /$ hari)

$\mathrm{T}=$ Koefisien Transmisivitas $\left(\mathrm{m}^{2} /\right.$ hari)

$\mathrm{D} \quad=$ Tebal akuifer $(\mathrm{m})$

Karakteristik ketebalan akuifer merupakan salah satu parameter yang digunakan dalam perhitungan data uji pemompaan. Nilai ketebalan ini didapatkan dari data log sumur dan unit litostratigrafi. Berikut merupakan persamaan menghitung debit maksimum (Persamaan 3):

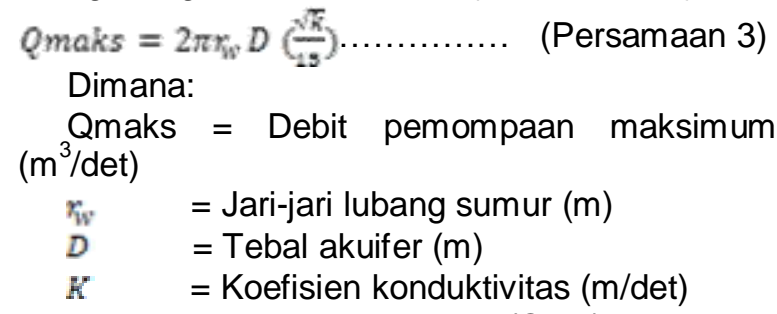

Perhitungan debit optimum (Qopt) atau debit aman akuifer pada suatu sumur, dihitung dengan menghitung $90 \%$ dari nilai debit maksimum yang didapat.

Tabel 1.Matriks tingkat potensi airtanah untuk airminum (SNI-13-7121, Tahun 2005)

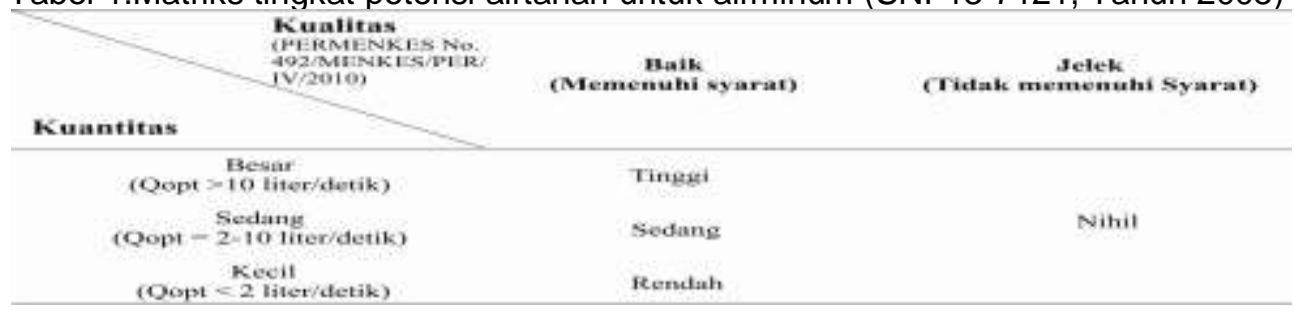

\section{Pembahasan}

Titik Minatan Sumur Gali, Titik Uji Kualitas, dan Uji Pemompaan

Dalam melakukan penelitian, data yang didapat berupa 45 titik minatan sumur gali yang menunjukan kedalaman akuifer bebas pada

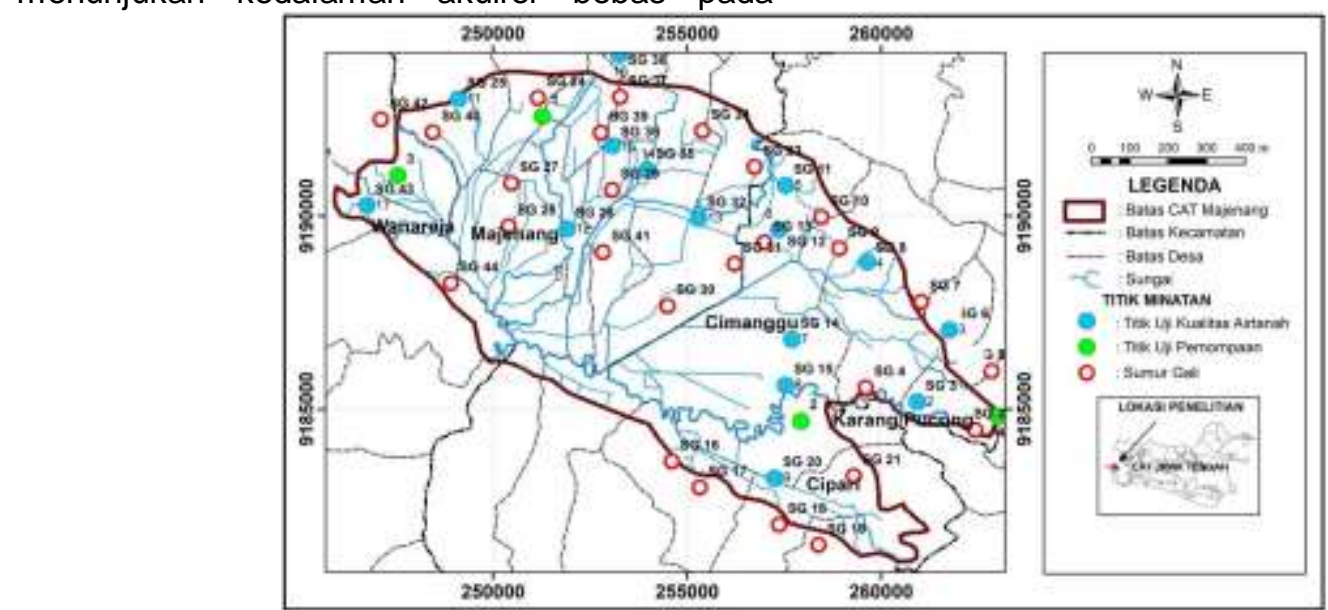

Gambar 4.Peta titik minatan sumur gali, uji kualitas dan uji pemompaan

\section{Zonasi Potensi Airtanah}

Berdasarkan kriteria kuantitas dan kualitasnya, daerah/wilayah potensi airtanah dapat dibedakan menjadi empat kategori ditunjukan pada Tabel 1.

a. Tinggi jika setiap sumur yang dibuat dengan jarak antarsumur tertentu menghasilkan Qopt lebih dari $10 \mathrm{~L} /$ det dengan kualitas airtanah baik.

b. Sedang jika setiap sumur yang dibuat dengan jarak antarsumur tertentu menghasilkan Qopt antara 2,0-10 L/det dengan kualitas airtanah baik.

c. Rendah jika setiap sumur yang dibuat dengan jarak antarsumur tertentu menghasilkan Qopt kurang dari 2,0 L/det dengan kualitas airtanah baik.

d. Nihil jika setiap sumur yang dibuat menghasilkan air dengan kualitas jelek

Dalam suatu wilayah kajian artanah yang di dalamnya dijumpai dua sistem akuifer, yakni sistem akuifer bebas dan tertekan, tangkat potensi airtanah di cekungan itu menjelaskan tingkat potensi pada setiap sistem akuifer tersebut. suatu daerah, uji kualitas pada 17 titik sumur gali yang dipilih berdasarkan persebarannya dan 4 lokasi uji pemompaan. Data ini tersebar dalam lingkungan CAT Majenang dan beberapa titik minatan terdapat pada daerah non CAT Majenang (Gambar.

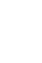




\section{Pola dan Arah Aliran Airtanah Bebas}

Dari hasil pengukuran pada 45 titik sumur gali yang tersebar di daerah penelitian diketahui kedalaman muka airtanah di daerah penelitian berkisar 0,1-4,5 mbmt dengan nilai muka airtanah sebesar 33,3-119,9 mdpl. Pola aliran airtanah bebas pada daerah ini terlihat mengalir dari daerah tepian (Kecamatan Karang Pucung, Kecamatan Wanareja dan bagian timurlaut Kecamatan Cimanggu) daerah penelitian menuju daerah tengah (Kecamatan Majenang) daerah penelitian, seperti yang diperlihatkan peta aliran MAT akuifer bebas daerah penelitian (Gambar. 5). Hal ini berhubungan dengan kondisi morfologi daerah penelitian, dimana pada bagian tepian CAT merupakan daerah dengan morfologi bergelombang dan pada daerah penelitian bagian tengah merupakan daerah dengan morfologi dataran.Banyak digunakannya sumur gali pada daerah penelitian, menjadi bukti bahwa pada daerah penelitian memiliki potensi airtanah bebas yang berada pada akuifer bebas.

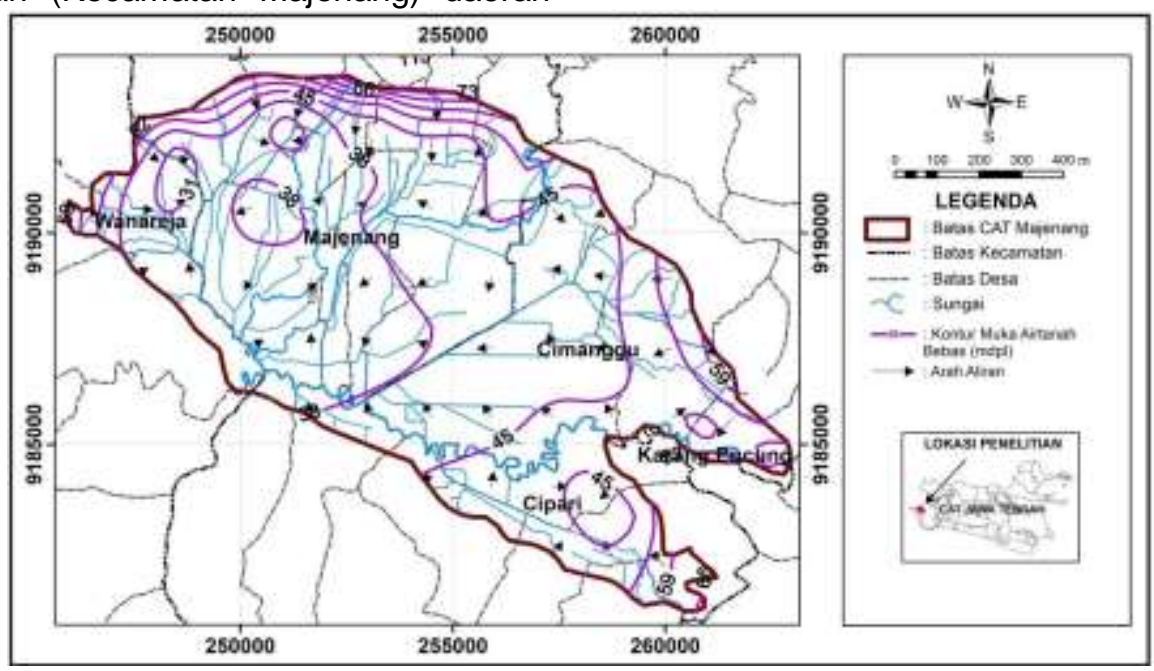

Gambar 5.Peta pola arah aliran dan kontur muka airtanah bebas CAT Majenang

\section{Uji Pemompaan/Pumping Test}

Uji pemompaan yang dilakukan untuk mengetahui kelulusan akuifer adalah dengan melakukan uji pemompaan menerus debit tetap (long period test). Pada penelitian ini didapatkan 4 data uji pemompaan dengan uji menerus.

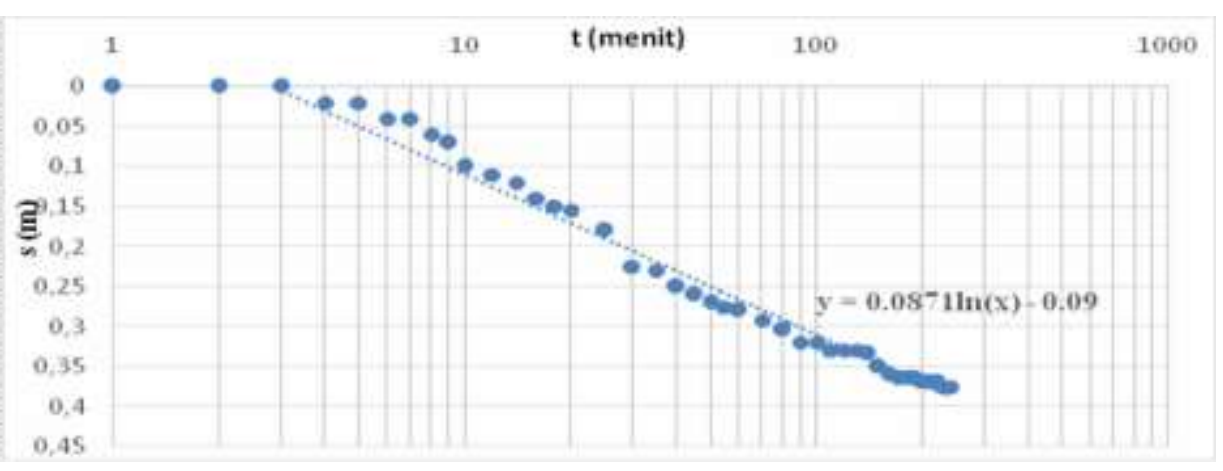

Gambar 6.Grafik uji pemompaan Sumur Gali Jenang

Dari grafik tersebut diperoleh nilai $\Delta S$ sebesar $0,22 \mathrm{~m}$ dan $\mathrm{t}_{0}$ sebesar 2,8 menit $\left(1,9 \times 10^{-3}\right.$ hari). Uji pemompaan dilakukan langsung pada sumur produksi, sehingga jarak yang terbentuk adalah 1 $\mathrm{m}$. Nilai tersebut merupakan hasil pendekatan yang dilakukan, karena sumur produksi dan sumur observasi sama.
Berdasarkan nilai $\Delta S$ dan $t_{0}$, didapat nilai perhitungan transmisivitas ( $\mathrm{T}$ ) sebesar 2,9 $\mathrm{m}^{2} /$ hari. Nilai konduktivitas hidrolika $(\mathrm{K})$ sebesar $0,4 \mathrm{~m} /$ hari. Nilai debit maksimum (Qmaks) dari hasil pengujian adalah 3,2 L/det dan nilai debit optimum (Qopt) sebesar 2,9 L/det. 


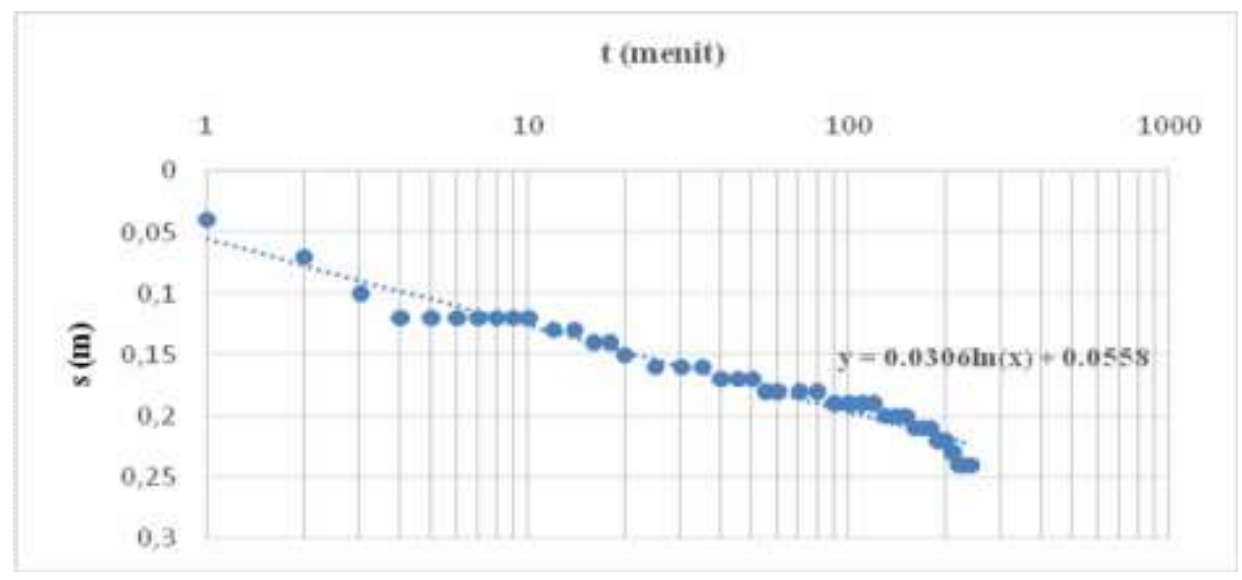

Gambar 7.Grafik uji pemompaan Sumur Gali Caruy

\section{Uji Pemompaan/Pumping Test}

Dari grafik tersebut diperoleh nilai $\Delta S$ sebesar $0,07 \mathrm{~m}$ dan $\mathrm{t}_{0}$ sebesar 0,2 menit $\left(1,1 \times 10^{-4}\right.$ hari $)$. Uji pemompaan dilakukan langsung pada sumur produksi, sehingga jarak yang terbentuk adalah 1 $\mathrm{m}$. Nilai tersebut merupakan hasil pendekatan yang dilakukan, karena sumur produksi dan sumur observasi sama.

Berdasarkan nilai $\Delta S$ dan $t_{0}$, didapat nilai perhitungan transmisivitas ( $\mathrm{T}$ ) sebesar 11,3 $\mathrm{m}^{2} /$ hari. Nilai konduktivitas hidrolika (K) sebesar $4,9 \mathrm{~m} /$ hari. Nilai debit maksimum (Qmaks) dari hasil pengujian adalah 3,6 L/det dan nilai debit optimum (Qopt) sebesar 3,3 L/det.

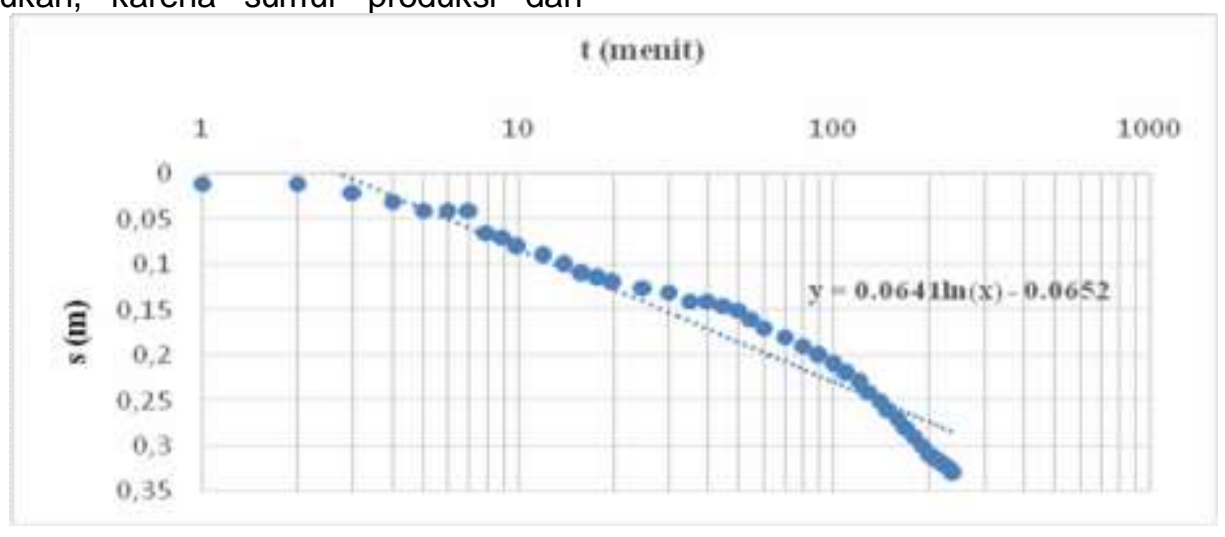

Gambar 8.Grafik uji pemompaan Sumur Gali Malabar

Dari grafik tersebut diperoleh nilai $\Delta S$ sebesar $0,13 \mathrm{~m}$ dan $\mathrm{t}_{0}$ sebesar 2,8 menit $\left(1,9 \times 10^{-3}\right.$ hari). Uji pemompaan dilakukan langsung pada sumur produksi, sehingga jarak yang terbentuk adalah 1 $\mathrm{m}$. Nilai tersebut merupakan hasil pendekatan yang dilakukan, karena sumur produksi dan sumur observasi sama.
Berdasarkan nilai $\Delta S$ dan $t_{0}$, didapat nilai perhitungan transmisivitas (T) sebesar $6 \mathrm{~m}^{2} /$ hari. Nilai konduktivitas hidrolika (K) sebesar 1,8 $\mathrm{m} /$ hari. Nilai debit maksimum (Qmaks) dari hasil pengujian adalah $3,2 \mathrm{~L} / \mathrm{det}$ dan nilai debit optimum (Qopt) sebesar 2,9 L/det. 


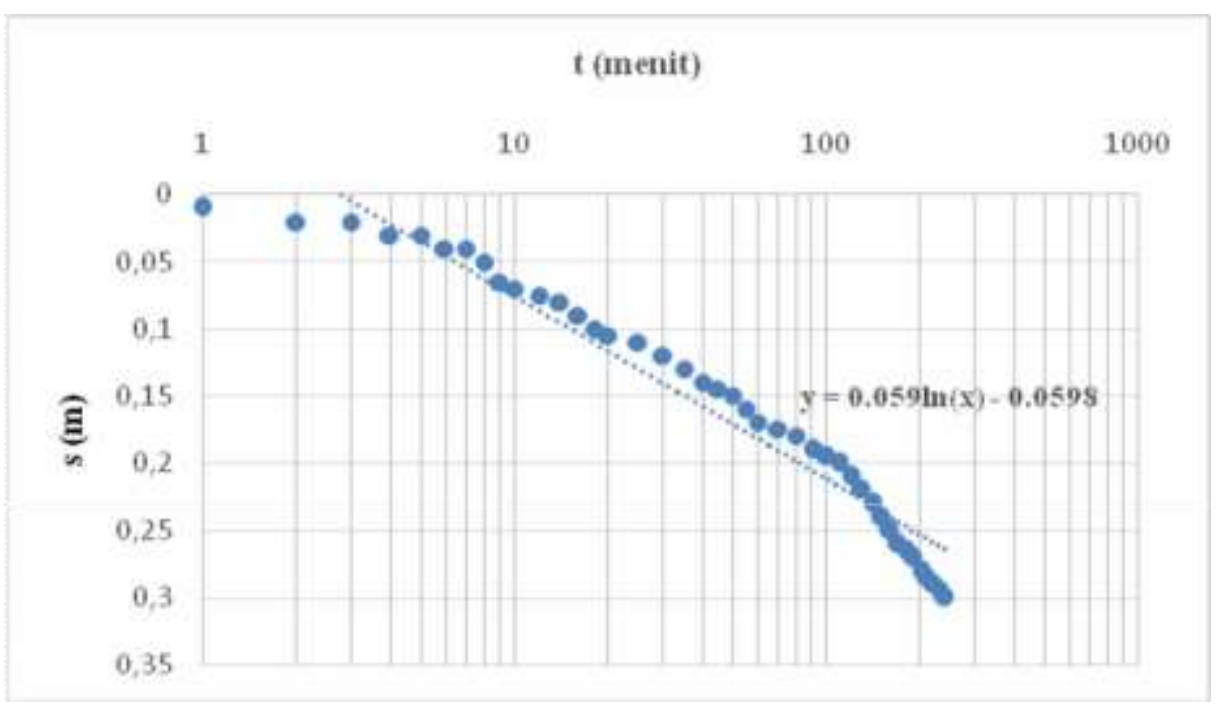

Gambar 9.Grafik uji pemompaan Sumur Gali Bantar Panjang

Dari grafik tersebut diperoleh nilai $\Delta S$ sebesar $0,12 \mathrm{~m}$ dan $\mathrm{t}_{0}$ sebesar2,7 menit $\left(1,9 \times 10^{-3}\right.$ hari $)$. Uji pemompaan dilakukan langsung pada sumur produksi, sehingga jarak yang terbentuk adalah 1 $\mathrm{m}$. Nilai tersebut merupakan hasil pendekatan yang dilakukan, karena sumur produksi dan sumur observasi sama.

Berdasarkan nilai $\Delta S$ dan $t_{0}$, didapat nilai perhitungan transmisivitas $(T)$ sebesar 6,3 $\mathrm{m}^{2} /$ hari. Nilai konduktivitas hidrolika $(\mathrm{K})$ sebesar $4 \mathrm{~m} /$ hari. Nilai debit maksimum (Qmaks) dari hasil pengujian adalah 2,3 L/det dan nilai debit optimum (Qopt) sebesar 2 L/det.

Berikut merupakan hasil analisis dari data uji pemompaan di 4 sumur gali daerah penelitian:

Tabel 2.Hasil uji pemompaan.

\begin{tabular}{ccccc}
\hline & \multicolumn{4}{c}{ Lokasi } \\
\cline { 2 - 5 } Parameter & $\begin{array}{c}\text { JENANG } \\
\mathbf{( 1 )}\end{array}$ & $\begin{array}{c}\text { CARUY } \\
\mathbf{( 2 )}\end{array}$ & $\begin{array}{c}\text { MALABAR } \\
\mathbf{( 3 )}\end{array}$ & $\begin{array}{c}\text { SG } \\
\text { BANTAR } \\
\text { PANJANG } \\
\mathbf{( 4 )}\end{array}$ \\
\cline { 2 - 5 } Transmisivitas & & 11,3 & 6,1 & 6,3 \\
$\left(\mathrm{~m}^{2} /\right.$ hari) & 2,9 & 4,9 & 1,8 & 3,9 \\
Konduktivitas (m/hari) & 0,7 & 3,6 & 3,2 & 2,3 \\
Qmax (L/detik) & 2,5 & 3,3 & 2,9 & 2,0 \\
Qopt (L/detik) & 2,2 & &
\end{tabular}

\section{Kualitas Airtanah}

Pada daerah penelitian, diketahui terdapat 17 titik lokasi pengambilan, dari 45 titik minatan, sampel airtanah yang sudah di uji kualitasnya. Secara keseluruhan, diketahui kondisi kualitas airtanah akuifer bebas di lokasi penelitian termasuk kategori baik atau layak untuk dijadikan air minum, namun secara setempat di beberapa lokasi menunjukan nilai besi $\left(\mathrm{Fe}^{3+}\right)$ dan $\mathrm{pH}$ yang berada di atas batas ambang yang ditentukan

\section{Zona Potensi Airtanah Bebas}

Berdasarkan datauji pemompaan pada CAT Majenang, dikeahui bahwa CAT Majenang memiliki potensi airtanah sedang pada akuifer bebas (Gambar. 10). Airtanah pada akuifer bebas umum ditemukan pada kedalaman 0,1-4,5
(Peraturan Menteri Kesehatan No. 492, Tahun 2010).

Berdasarkan data uji kualitas (Tabel 3), pada daerah penelitian terdapat 9 titik minatan yang tidak memenuhi kategori untuk air minum. Lima titik yang tidak memenuhi pada parameter $\mathrm{pH}$ adalah titik SG-8, SG-25, SG-38 dan SG-43.Tiga titik yang tidak memenuhi pada parameter $\mathrm{Fe}^{3+}$ adalah titik SG-12, SG-14 dan SG-22.Tiga titik yang tidak memenuhi parameter warna adalah titik SG-12, SG-28 dan SG-32. mbmt. Nilai muka airtanah jika dibandingkan dengan elevasi daerah penelitian diketahui sebesar 33,3-119,9 mdpl. Dalam uji kualitas, diketahui terdapat beberapa titik yang memiliki parameter yang melebihi yang diperbolehkan oleh Peraturan Menteri Kesehatan No. 492, Tahun 2010, tetapi dalam pembuatan peta 
zonasi potensi airtanah akuifer bebas, parameter kualitas tidak diperhitungkan.

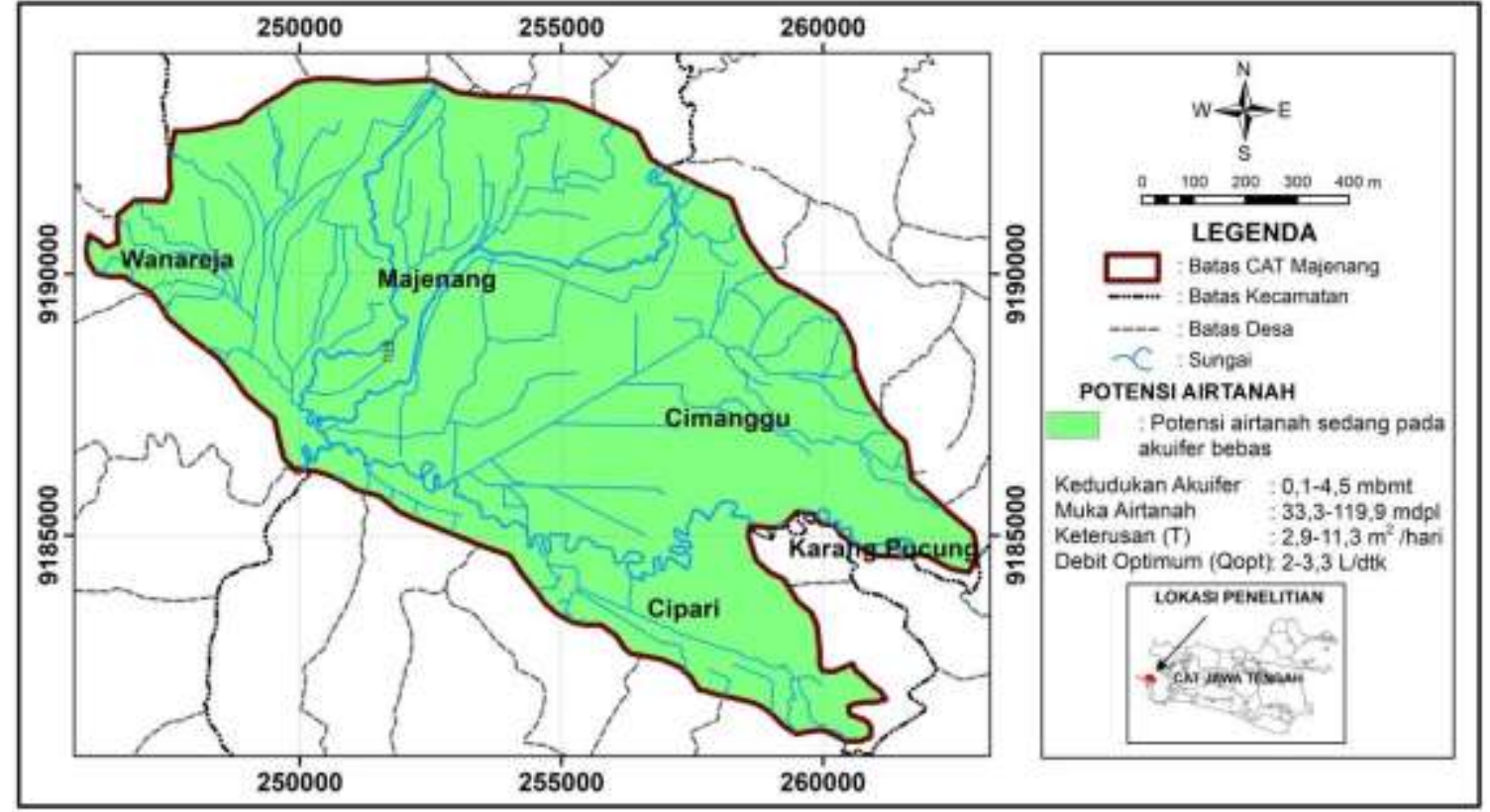

Gambar 10.Peta Potensi Airtanah Bebas CAT Majenang

\section{Kesimpulan}

Berdasarkan hasil penelitian diketahui bahwa muka airtanah bebas CAT Majenang memiliki nilai 33,3-119,9 mdpl. Arah aliran muka airtanah akuifer bebas diketahui berasal dari daerah tepian CAT menuju daerah tengah CAT. Hasil uji kualitas di daerah penelitian menunjukan bahwa pada beberapa lokasi di CAT Majenang memiliki nilai $\mathrm{pH}$ dan $\mathrm{Fe}^{3+}$ yang melebihi batas untuk menjadi air minum.Dalam pembuatan peta zonasi potensi airtanah, hanya digunakan data kuantitas, sehingga diketahui CAT Majenang.termasuk dalam potensi sedang (Qopt $=2-10 \mathrm{~L} /$ detik).

Berdasarkan peta potensi, diketahui bahwa pada lokasi penelitian, memiliki kuantitas airtanah dengan potensi sedang, sehingga airtanah dapat dimanfaatkan secara optimal melalui sumur gali dengan debit optimum yang dapat diambil sebesar $172.800 \mathrm{~L} /$ hari/sumur.

\section{Daftar Pustaka}

Badan Pusat Statistik Kabupaten Cilacap. 2016. Kabupaten Cilacap Dalam Angka 2016. Cilacap.

Badan Pusat Statistik Kabupaten Cilacap. 2016. Kecamatan Cimanggu Dalam Angka Tahun 2016, Cilacap.

Badan Pusat Statistik Kabupaten Cilacap. 2016. Kecamatan Cipari Dalam Angka Tahun 2016, Cilacap.

Badan Pusat Statistik Kabupaten Cilacap. 2016. Kecamatan Karangpucung Dalam Angka Tahun 2016, Cilacap.
Badan Pusat Statistik Kabupaten Cilacap. 2016. Kecamatan Majenang Dalam Angka Tahun 2016, Cilacap.

Badan Pusat Statistik Kabupaten Cilacap. 2016. Kecamatan Wanareja Dalam Angka Tahun 2016, Cilacap.

Direktorat Jenderal Cipta Karya. 1996. Standar Kebutuhan Air Bersih Untuk Keperluan Rumah Tangga, Jakarta.

Kastowo dan Suwarna. 1996. Peta Geologi Lembar Majenang, Jawa Tengah. Pusat Penelitian dan Pengembangan Geologi, Bandung.

Kumar, T. J. R., Balasubramanian, A., Kumar, R. S., Dushiyanthan, C., Thiruneelakandan, B., Suresh, R., Karthikeyan, K., dan Davidraju, D. 2014. Assesment of Groundwater Potential Based on Aquifer Properties of Hard Rock terrain in the Chittar-Uppodai Watershed, Tamil Nadu, India. Journal Applied Water Science, Volume 6, Issue 2, pg. 179-186.

Peraturan Menteri ESDM No. 2 Tahun 2017 tentang Cekungan Airtanah $\mathrm{Di}$ Indonesia. Jakarta.

Peraturan Menteri Kesehatan No. 492 Tahun 2010 tentang Persyaratan Kualitas Air Minum. Jakarta.

Standar Nasional Indonesia 13-7121 Tahun 2005 tentang Penyelidikan potensi airtanah skala 1:100.000 atau lebih besar.

Tabrani, A. 1994.Peta Hidrogeologi Regional Lembar Pekalongan, Jawa Tengah.Departemen Energi dan Sumber Daya Mineral, Jawa Tengah. 
Promine Journal, June 2017, Vol. 5 (1), page 41 - 50

Tabel 3. Kualitas airtanah daerah penelitian

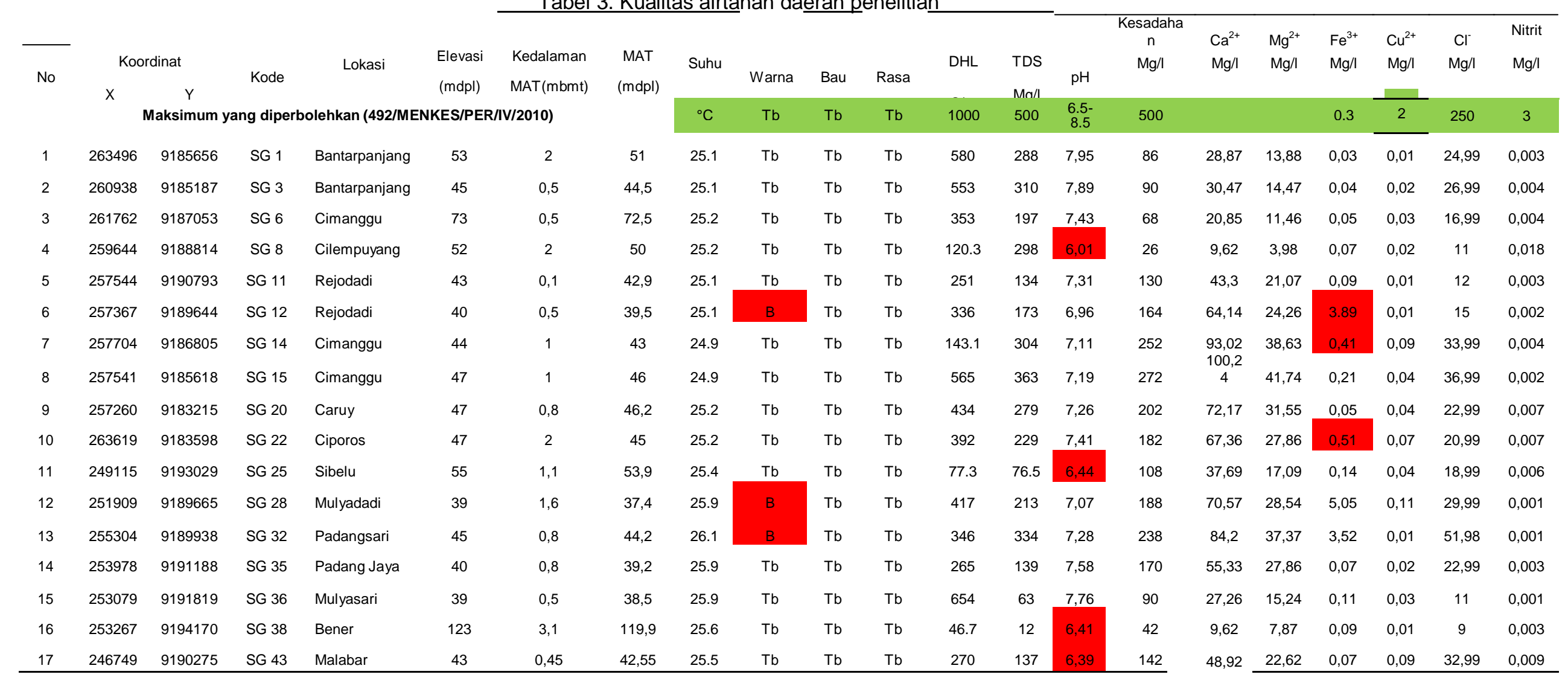

Keterangan : $\mathrm{Tb} \quad$ : Tidak berwarna/berasa/berbau

B $\quad: \quad \begin{aligned} & \text { Berwarna/berasa/berbau } \\ & \text { Nilai berada di atas batas yang } \\ & \text { ditentukan }\end{aligned}$


Lampiran-Data Sumur Gali

\begin{tabular}{|c|c|c|c|c|c|c|c|}
\hline No & Kode & $\mathbf{X}$ & $\mathbf{Y}$ & $\begin{array}{l}\text { Elevasi } \\
\text { (mdpl) }\end{array}$ & $\begin{array}{l}\text { Kedalaman } \\
\text { MAT (mbmt) }\end{array}$ & $\begin{array}{c}\text { MAT } \\
\text { (mdpl) }\end{array}$ & Keterangan \\
\hline 1 & SG 1 & 263496 & 9185656 & 53 & 2 & 51 & Sampel Air \\
\hline 2 & SG 2 & 262433 & 9184465 & 47 & 2 & 45 & - \\
\hline 3 & SG 3 & 260938 & 9185187 & 45 & 0.5 & 44.5 & Sampel Air \\
\hline 4 & SG 4 & 259610 & 9185558 & 47 & 0.4 & 46.6 & - \\
\hline 5 & SG 5 & 262852 & 9185983 & 64 & 0.5 & 63.5 & - \\
\hline 6 & SG 6 & 261762 & 9187053 & 73 & 0.5 & 72.5 & Sampel Air \\
\hline 7 & SG 7 & 261041 & 9187778 & 61 & 0.3 & 60.7 & - \\
\hline 8 & SG 8 & 259644 & 9188814 & 52 & 2 & 50 & Sampel Air \\
\hline 9 & SG 9 & 258928 & 9189160 & 45 & 0.1 & 44.9 & - \\
\hline 10 & SG 10 & 258470 & 9189974 & 43 & 0.2 & 42.8 & - \\
\hline 11 & SG 11 & 257544 & 9190793 & 43 & 0.1 & 42.9 & Sampel Air \\
\hline 12 & SG 12 & 257367 & 9189644 & 40 & 0.5 & 39.5 & Sampel Air \\
\hline 13 & SG 13 & 256999 & 9189317 & 41 & 0.3 & 40.7 & - \\
\hline 14 & SG 14 & 257704 & 9186805 & 44 & 1 & 43 & Sampel Air \\
\hline 15 & SG 15 & 257541 & 9185618 & 47 & 1 & 46 & Sampel Air \\
\hline 16 & SG 16 & 254613 & 9183651 & 48 & 1 & 47 & - \\
\hline 17 & SG 17 & 255334 & 9182975 & 51 & 2 & 49 & - \\
\hline 18 & SG 18 & 257379 & 9182014 & 52 & 0.8 & 51.2 & - \\
\hline 19 & SG 19 & 258395 & 9181483 & 50 & 1 & 49 & - \\
\hline 20 & SG 20 & 257260 & 9183215 & 47 & 0.8 & 46.2 & Sampel Air \\
\hline 21 & SG 21 & 259306 & 9183271 & 50 & 4.5 & 45.5 & MAT \\
\hline 22 & SG 22 & 263619 & 9183598 & 47 & 2 & 45 & Sampel Air \\
\hline 23 & SG 23 & 263377 & 9183605 & 44 & 0.5 & 43.5 & - \\
\hline 24 & SG 24 & 251161 & 9193057 & 34 & 0.6 & 33.4 & - \\
\hline 25 & SG 25 & 249115 & 9193029 & 55 & 1.1 & 53.9 & Sampel Air \\
\hline 26 & SG 26 & 250412 & 9189736 & 38 & 0.5 & 37.5 & - \\
\hline 27 & SG 27 & 250476 & 9190846 & 42 & 0.85 & 41.15 & - \\
\hline 28 & SG 28 & 251909 & 9189665 & 39 & 1.6 & 37.4 & Sampel Air \\
\hline 29 & SG 29 & 253073 & 9190673 & 39 & 0.6 & 38.4 & - \\
\hline 30 & SG 30 & 254504 & 9187669 & 39 & 1 & 38 & - \\
\hline 31 & SG 31 & 256227 & 9188765 & 44 & 0.7 & 43.3 & MAT \\
\hline 32 & SG 32 & 255304 & 9189938 & 45 & 0.8 & 44.2 & Sampel Air \\
\hline 33 & SG 33 & 256745 & 9191268 & 52 & 0.6 & 51.4 & - \\
\hline 34 & SG 34 & 255400 & 9192206 & 44 & 0 & 44 & - \\
\hline 35 & SG 35 & 253978 & 9191188 & 40 & 0.8 & 39.2 & Sampel Air \\
\hline 36 & SG 36 & 253079 & 9191819 & 39 & 0.5 & 38.5 & Sampel Air \\
\hline 37 & SG 37 & 253280 & 9193077 & 60 & 3.7 & 56.3 & MAT \\
\hline 38 & SG 38 & 253267 & 9194170 & 123 & 3.1 & 119.9 & Sampel Air \\
\hline 39 & SG 39 & 252784 & 9192154 & 41 & 0.5 & 40.5 & - \\
\hline 40 & SG 40 & 248454 & 9192169 & 35 & 1.7 & 33.3 & - \\
\hline 41 & SG 41 & 252835 & 9189062 & 38 & 1.1 & 36.9 & - \\
\hline 42 & SG 42 & 247117 & 9192497 & 67 & 3 & 64 & - \\
\hline 43 & SG 43 & 246749 & 9190275 & 43 & 0.45 & 42.55 & Sampel Air \\
\hline 44 & SG 44 & 248921 & 9188259 & 40 & 2.9 & 37.1 & - \\
\hline 45 & SG 45 & 245047 & 9188885 & 76 & 0.4 & 75.6 & - \\
\hline 46 & SG Jenang & 251276 & 9192578 & 46.7 & 0.9 & 45.8 & Uji Pemompaan \\
\hline 47 & SG Caruy & 257936 & 9184688 & 38 & 1.85 & 36.15 & Uji Pemompaan \\
\hline 48 & SG Malabar & 247550 & 9191050 & 32 & 2.48 & 29.52 & Uji Pemompaan \\
\hline 49 & SG Bantar Panjang & 263013 & 9184810 & 45 & 4.5 & 40.5 & Uji Pemompaan \\
\hline
\end{tabular}

